\title{
LA RUPTURA FUNERARIA DEL POMERIUM DESDE SU NACIMIENTO Y HASTA SU DESAPARICIÓN. ENTERRAMIENTOS IN URBE
}

\author{
Manuel Dionisio Ruiz Bueno \\ Universidad de Córdoba
}

\begin{tabular}{ll}
\hline Recibido: $07 / 02 / 2013$ & Aceptado: $11 / 02 / 2013$ \\
Revisado: $07 / 02 / 2013$ & Publicado: $17 / 06 / 2013$
\end{tabular}

\section{RESUMEN}

El objetivo de la presente contribución es exponer la evolución, desde una perspectiva funeraria, de uno de los límites más característicos de las ciudades romanas, es decir, el pomerium. Gracias a un variado elenco de testimonios arqueológicos y textuales procedentes, principalmente, de la Italia Annonaria y, en especial, de Hispania, se ha podido restituir el nacimiento, consolidación y decadencia de dicho límite.

Un proceso que se prolongó durante varios siglos, y que no sólo supuso la pérdida de su significado original, sino, sobre todo, la aparición de enterramientos dentro del pomerium (in urbe). Sepulturas que, en un primer momento, fueron excepcionales y minoritarias pero que, con el paso del tiempo y debido a varios factores, acabaron generalizándose a lo largo de la Antigüedad Tardía.

Palabras Clave

Pomerium, Enterramientos, Sepulturas, Tumbas, In Urbe, Intra Moenia, Intramuros.
ABSTRAC

The aim of this contribution is to show the evolution, from a funerary perspective, of one of the most characteristic limits of the roman cities, that is to say, the pomerium. Thanks to a wide variety of archeological testimonies and documented writings, mainly from the Italia Annonaria and, specially, Hispania, it has been possible to restore the rise, development, and decadence of that limit.

That process, which extended through some centuries, involved not only the loss of its initial meaning, but mainly, the emergence of graves inside the pomerium (in urbe). At first, those burials were exceptional and for minorities, but due to different reasons, they became common in the Late Antiquity.

\section{KEYWORDS}

Pomerium, Burials, Graves, In Urbe, Intra moenia, Within the Walls.

1 El presente artículo forma parte de una investigación más amplia que estamos desarrollando en el marco de nuestro Doctorado,focalizado en el estudio de las transformaciones topográficas que tuvieron lugar en la superficie in urbe de las principales ciudades béticas durante la Antigüedad Tardía (con especial atención al caso de Córdoba)-, financiado mediante una Beca de Formación del Profesorado Universitario (FPU) y dirigido por el prof. Dr. Desiderio Vaquerizo Gil.

Una labor de análisis e interpretación inserta a su vez dentro del Proyecto de Investigación del Grupo PAIDI HUM-236 "De la urbs a la civitas: transformaciones materiales e ideológicas en suelo urbano desde la etapa clásica al Altomedievo. Córdoba como laboratorio", financiado por la Dirección General de Investigación y Gestión del Plan Nacional I+D+I. Ministerio de Ciencia e Innovación. Gobierno de España, en su convocatoria de 2010 (Ref.: HAR2010-16651; Subprograma HIST) y dirigido también por el prof. Dr. Desiderio Vaquerizo Gil. 


\section{INTRODUCCIÓN}

Entre los principales elementos característicos de las ciudades romanas no podemos olvidar dos límites sacros con un gran significado ideológico: el pomerium y el sulcus primigenius (Fig. 1). El primero era una línea finita, invisible y cerrada que delimitaba una superficie (urbs); el segundo era una línea abierta, obtenida mediante el trazado de un surco por fuera del trazado anterior, monumentalizada a través de la construcción de un recinto amurallado que seguía su recorrido, e interrumpida en determinados puntos perfectamente regulados y orientados, es decir, las puertas (Annibaletto, 2010, 32-35). Precisamente, dada la cercanía de ambos límites, éstos tendieron a superponerse desde una perspectiva espacial ${ }^{1}$ en la mayor parte de los núcleos urbanos, salvo honrosas excepciones como el municipium hispano de Munigua (Schattner, 2003, 60) o la propia Roma, donde desde el siglo VI a.C. hasta la segunda mitad del III d.C. siguieron recorridos divergentes (Annibaletto, 2010, 132).

Entre las distintas funciones del pomerio nos interesa su carácter diferenciador entre el espacio inaugurato (urbs) y el que no lo era (suburbium y ager), al quedar vetadas las actividades con una carga negativa, incluyendo las funestas, dentro de la urbs. Esta clara separación entre un mundo dedicado exclusivamente a los vivos y otro en el que coexistían actividades diversas (funerarias, domésticas o artesanales) se basó inicialmente en una serie de fundamentos de diversa índole:

$\left.1^{\circ}\right)$ Religiosos. Para F. Casavola ${ }^{2}$ (citado en López Melero, 1997, 111), las motivaciones sacras fueron las más importantes, ya que la muerte suponía un hecho impuro que podía contagiar las cosas puras, siendo necesario limitarla a un espacio específico. Cuando no se podía evitar este fatídico destino en el interior de las murallas, era obligatorio poner en marcha una serie de ritos de purificación con el fin de mantener el "bienestar" de la comunidad, en especial de sacerdotes y magistrados.

$\left.2^{\mathrm{o}}\right)$ Legales. El único modo de proteger los derechos de la comunidad cívica en su conjunto, de los particulares y, por último, de los propios muertos fue establecer unos emplazamientos específicos

1 De ahí que, por lo general, los investigadores tendamos a utilizar, de forma indistinta, vocablos como pomerium y sulcus/mura, al igual que los términos in urbe, intra moenia o intramuros.

2 F. Casavola (1958): Studi sulle azioni popolari romane, Napoli. destinados a los fallecidos. Ni los espacios públicos (a excepción de los dedicados en exclusiva a dicho fin), ni las propiedades particulares de una persona (salvo expreso deseo de su propietario) podían ser el lugar de descanso final de la población (Fernández Fernández, 1989, 84-85), ya que en cualquiera de dichas circunstancias las tumbas no estaban protegidas por el derecho romano.

$3^{\circ}$ ) Pragmáticos. Diversos autores clásicos adujeron razones prácticas, como el peligro de incendio derivado de la localización de los ustrina dentro de la ciudad $\left(\right.$ Cicerón $^{3}$ ), o higiénico-sanitarias (Isidoro de Sevilla $\left.{ }^{4}\right)$, si bien, R. López Melero $(1997,110)$ considera el planteamiento del obispo hispalense demasiado racionalista y "poco consonante con la realidad sociológica de la época”.

$4^{\mathrm{o}}$ ) ¿Económicos? Para la mentalidad romana cualquier sitio donde se producía una deposición funeraria pasaba a convertirse en locus religiosus, por lo que a la hora de venderlo su precio no podía ser el mismo que el de un locus purus. Aunque este factor no ha sido analizado directamente por otros investigadores, quizás también motivó la exclusión del orbe fúnebre de la urbs, limitándolo a espacios cercados en el suburbio y el territorio. En este sentido, según ha señalado R. M. ${ }^{a}$ Fernández Fernández $(1989,85)$, si en un espacio agrícola acaecía un rito asociado a la muerte, a partir de ese momento ya no se podía cultivar más (por lo que perdía parte de su valor económico), panorama que, con matices, pudo extrapolarse al interior de la urbe.

\section{Evolución del POMERIUM DEL SIgLo VIII A.C. AL VIII D.C.}

\section{1. SigLOS VIII-V A.C. LA INSTAURACIÓN DE} UN NUEVO MODUS VIVENDI

La primera ciudad que se dotó conjuntamente de pomerio y sulcus fue Roma, en concreto con motivo de su mítica fundación por parte de Rómulo, quien, en el segundo cuarto del siglo VIII a.C., decidió llevar a cabo dicha empresa en una zona ya habitada que recibía el nombre de Septimontium. Para ello decidió aunar y combinar un límite sacro de origen latino (pomerium) con otro de procedencia etrusca (sulcus), dando como resultado un ritual fundacional genérico que acabó empleándose en la fundación de cualquier núcleo urbano por

3 De Legibus. 2, 58 (Blasi, 2008, 1047).

4 Etymologiae. 15.11.1 (López Melero, 1997, 110). 
parte del Estado, y que implicó el establecimiento de una superficie dedicada en exclusiva al mundo de los vivos.

No obstante, desde un punto de vista legislativo debemos remontarnos hasta mediados del siglo $\mathrm{V}$ a.C. (451- 449 a.C.) para encontrarnos ante el testimonio jurídico más antiguo donde se recoge la obligatoriedad de enterrar a los fallecidos al exterior del pomerio (Lambert, 1997, 285). Se trata de la Tabula X, 1 de la conocida como "Ley de las Doce Tablas", cuya promulgación se ha interpretado tradicionalmente como un síntoma evidente tanto de la existencia de sepulturas intra moenia, como de la necesidad de poner fin a dicha práctica. No obstante, para M. Annibaletto $(2010,53)$ su fin principal no era limitar comportamientos ilegales, sino "fissare in forma scritta regole antichissime comunemente seguite e sentite come fondamento del vivere romano".

En otro orden de cosas, debemos tener en cuenta que, desde un primer momento, existieron algunos individuos ${ }^{5}$ que, de manera excepcional, pudieron descansar eternamente en la superficie in urbe. Salvedades documentadas desde un punto de vista arqueológico y literario que fueron toleradas durante toda la República y el Imperio como veremos a continuación.

En primer lugar los clari viri, es decir, determinados individuos (incluyendo sus descendientes) que al haber realizado hechos excepcionales -virtutis causa- gozaron del derecho de recibir sepultura en plena urbs (Arce, 1990, 88). Entre los ejemplos más antiguos tenemos a los cónsules Postumio Tuberto $(† 508$ a.C.) o Publio Valerio Publicola $(† 503$ a.C.), cuyo privilegiado lugar de enterramiento aún era recordado por historiadores como Cicerón, Dionisio de Halicarnaso, Plutarco o Tito Livio (Blasi, $2008,1050)$. A priori puede resultar llamativo que ambos falleciesen antes de la publicación de la Lex XII tabularum; sin embargo, contamos con otros ejemplos datados en pleno siglo III a.C. (vid. in$\mathrm{fra}$ ); es decir tras la promulgación de dicho texto jurídico.

5 Hemos dejado fuera del estudio a las vírgenes Vestales o a las parejas de galos y griegos enterrados vivos en tres ocasiones $(228,216$ y 113 a.C.) en un espacio del Foro Boario con el fin de conjurar los peligros externos que amenazaban a la ciudad (Carafa, 2008, 676), ya que se trata de peculiaridades exclusivas de la "ciudad eterna" y que responden a fundamentos y motivaciones diferentes.

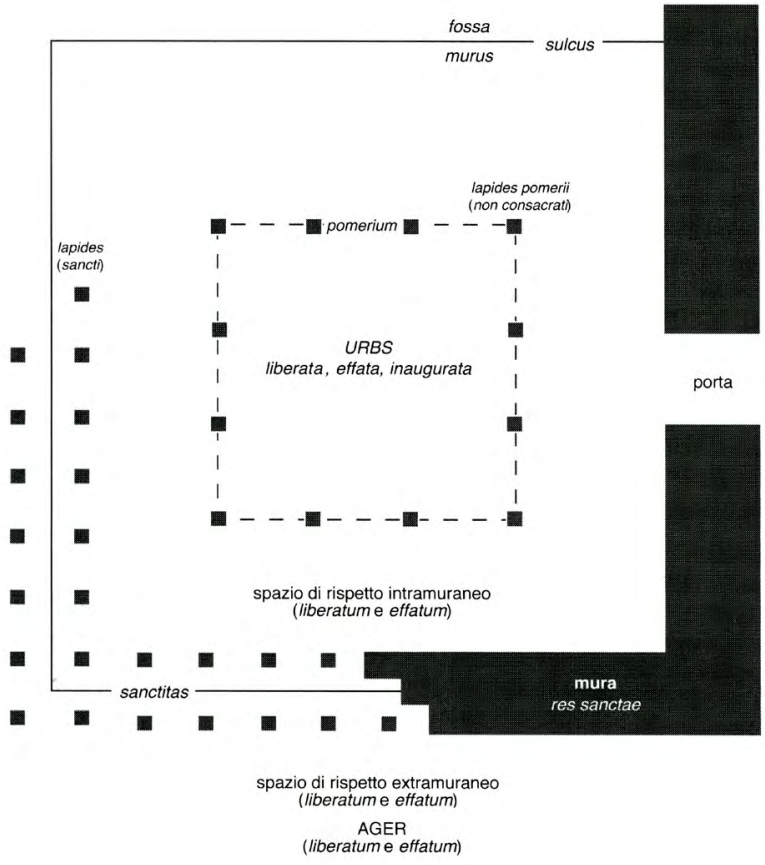

Fig. 1. Concepción inicial de los dos límites sacros de toda ciudad (Annibaletto, 2010, 39).

En segundo lugar aquellos fallecidos con menos de 40 días de vida ${ }^{6}$, quienes podían yacer dentro de las casas o junto a éstas (con independencia de la ubicación de las viviendas dentro o fuera del pomerio), concretamente en el acceso al atrio, en el peristilo o debajo del tejadillo de toda puerta abierta al patio -conocido con el nombre de sub grundo-, ya que para el ius pontificium dichos individuos no eran considerados seres humanos (López Melero, 1997, 113). A la hora de explicar las motivaciones de esta modalidad de enterramiento se han planteado variadas repuestas como el deseo de reforzar la cohesión de la unidad familiar o fortalecer las relaciones públicas (puesto que la casa era el principal escenario de dichas actividades); el anhelo de facilitar un futuro renacimiento; una mera señal de negación de los padres a la hora de desprenderse por completo de sus hijos, etc. (Sevilla 2010-2011, 204).

Dentro de este grupo incluimos aquellos individuos (infantiles en su mayor parte) sepultados durante la fundación o destrucción de inmuebles públicos o privados y que deben ponerse en relación con rituales de fuerte valor simbólico. Acerca

6 Aunque según A. Sevilla $(2010,200-201)$, "no se tardó en confundir a los bebés de menos de 40 días con otra categoría de infantes: aquéllos a los que no les habían salido el primer diente"; es decir, los menores de 7 meses. 
de su interpretación para investigadores como A. Carandini $(2008,706)$, P. Carafa $(2008,675-677)$ o A. Sevilla (2010-2011, 205) son ejemplos o reminiscencias de sacrificios infantiles. Desde un punto de vista cronológico, los ejemplos más antiguos en el Caput Mundi se llevan a los siglos VIII y VII a.C., habiéndose identificado tanto dentro -Palatino- como fuera -Capitolio o Foro Romano- del primigenio pomerium (Carafa, 2008; Gusberti, 2008).

\section{2. SigLo IV A.C - II D.C. CONSOLIDACIÓN Y AUGE DEL MODELO}

Esta etapa conoció una profusa legislación que, por lo general, no hizo más que ratificar la derivación del mundo de los muertos al suburbium. Entre los textos más antiguos tenemos el decreto emitido por el Senado ${ }^{7}$ hacia mediados del siglo III a.C., de cuyas líneas se extrae que parte de la clase aristocrática continuó apostando por la sepultura intra moenia como modo de reforzar la unión familiar y el nexo con el pasado a través de la proximidad topográfica entre hábitat y lugar de descanso final. Dicha modalidad debió alcanzar tonos preocupantes, pues el Senado se vio obligado a intervenir (Annibaletto, 2010, 54), siendo tan sólo permitida a algunos hombres que habían destacado por sus hazañas como el político y militar Gaio Gabricio Luscino (†275 a.C.), (Blasi, 2008, 1048).

Si dejamos a un lado el capítulo 73 de la Lex Ursonensis (44 a.C.), donde, "en ningún caso se permite enterrar dentro del recinto amurallado de la colonia ursonensis" (Fernández Fernández, 1989, 80), el siguiente hito jurídico se sitúa en las primera décadas del siglo II d.C., cuando se promulgó el Corpus Iuris Civilis, vol. I, Digesta, XLVII, 12, 3 (117-138 d.C.). La importancia de esta ley es que, por primera vez, se impuso un castigo al magistrado responsable de permitir las inhumaciones intra moenia (Fernández Fernández, 1989, 83), ordenándose además el traslado inmediato de aquellos fallecidos ilegalmente inhumados o cremados dentro de la civitas (López Melero, 1997, 113-114). Asimismo, esta disposición refleja la existencia de comunidades -se ignora cuáles- cuyas leyes particulares permitían los enterramientos in urbe (Lambert, 1997, 287), lo que desencadenó un debate entre los juristas acerca de la "superior autoridad -o no- de las disposiciones de los emperadores, sobre

7 Servius Honoratus (in Vergilii) Aeneidos libros. 11, 206 (Annibaletto, 2010, 54). las leyes particulares de las comunidades" (Fernández Fernández, 1989, 90).

A lo largo del siglo II d.C. contamos con otras medidas legislativas -Constitutiones de Antonino Pío (138-161 d.C.) y Marco Aurelio (161-180 d.C.)que reflejan el incumplimiento de la legislación ${ }^{8}$.

La minoritaria e intermitente, pero continua, invasión funeraria de la urbs por parte de sepulcros ajenos a las excepciones permitidas, quizás se pueda poner en relación con la propia modificación y superación del término pomerium como límite sacro. Para M. Annibaletto (2010, 84 y 111), a partir de época tardorrepublicana el concepto originario se vio sometido a una cierta tergiversación y simplificación debido a una utilización indistinta de sulcus y pomerio; a la visión del segundo como un espacio'; a la concepción -a partir del siglo II d.C.de las murallas como sanctae debido no a su carácter sacro, sino a la sanción derivada de cualquier acto contrario a la reglamentación y, por último, al incremento del peso de lo profano sobre lo sacro a la hora de separar las esferas urbana y suburbana.

Lamentablemente, desde un punto de vista arqueológico los testimonios de sepulturas intra moenia con los que contamos para momentos tardorrepublicanos y altoimperiales se limitan únicamente a inhumaciones permitidas por la legislación.

Por un lado, como ejemplos más significativos de clari viri tenemos a varios emperadores ${ }^{10}$ de la dinastía Flavia y Antonina, quienes se arrogaron el derecho de yacer para la perpetuidad dentro de las murallas debido a una concepción autocrática del poder (Arce, 1990, 88-89). Por otro, en regiones como la Península Ibérica contamos con un variado elenco de yacimientos donde se han identificado niños enterrados tanto en el interior o en el exterior de viviendas privadas -Carmo (Román Rodríguez, 2009, 3140), Bilbilis, Celsa y Veleia (Mínguez Morales, 1989-1990; Sevilla, 2010-2011, 202 y 203)-

8 M. Annibaletto $(2010,120)$ plantea una posible conexión entre esta persistente repetición de la ley y la casuística propia de Roma -cuyo pomerio se amplió de forma continua desde el siglo VI a.C. al III d.C.-, por lo que áreas hasta entonces ocupadas por propiedades residenciales y actividades nocivas (residuos urbanos, cementerios, etc.) pasaron a formar parte de la ciudad, siendo necesario "erradicar" su carácter suburbano mediante una continua reiteración de la prohibición.

9 Frente a la idea primigenia según la cual se trataba de una línea o límite sacro.

10 El ejemplo más paradigmático es el del Marco Ulpio Trajano († 117 d.C.), enterrado en la base de la columna honorífica homónima. 

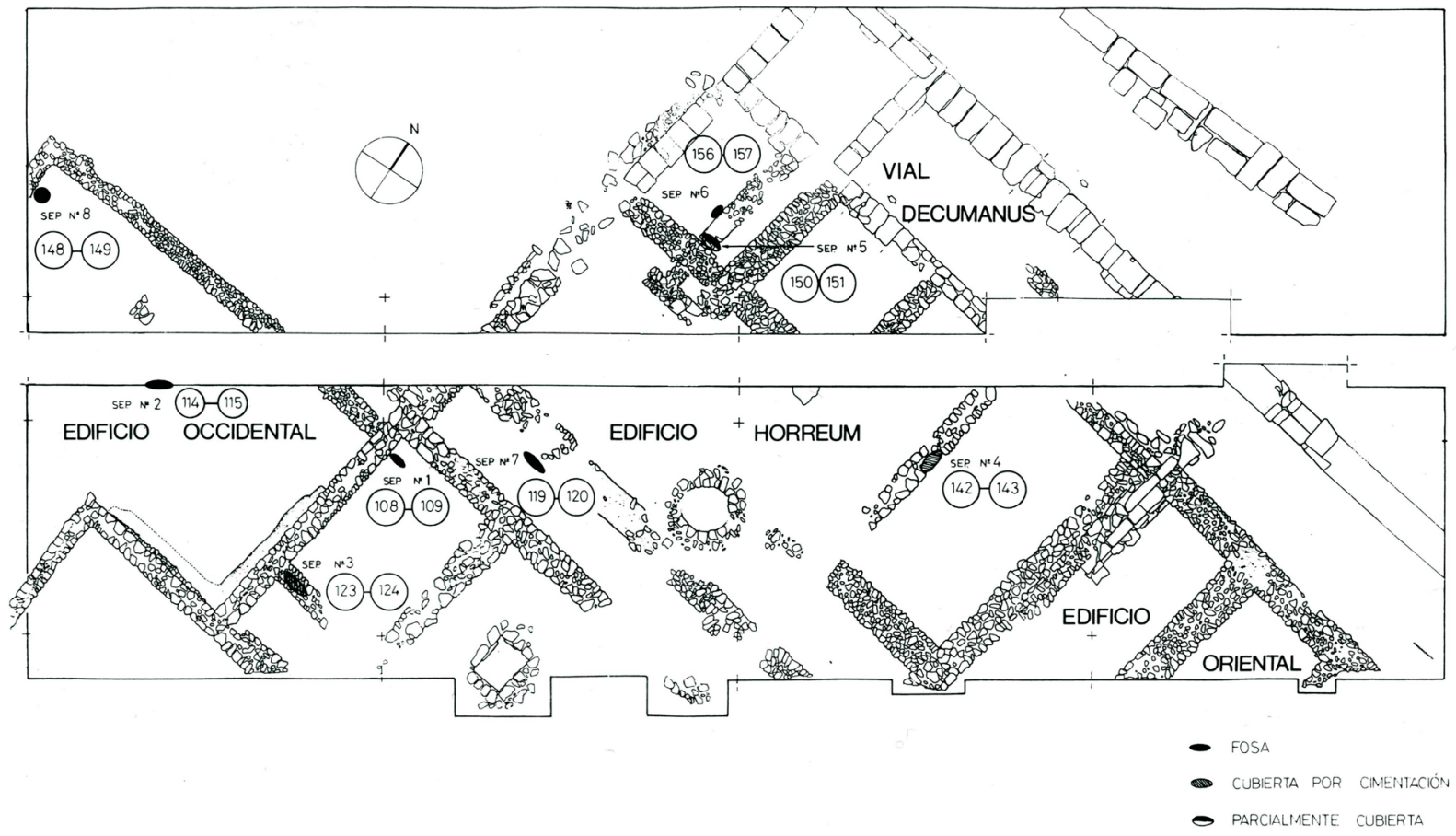

Fig. 2. Dianium. Inhumaciones infantiles fundacionales practicadas en el "Edificio Horreum" y en el "Edificio Occidental” (Gisbert y Sentí, 1989, 104).

como con motivo de la fundación o destrucción de inmuebles públicos (en especial horrea) -Carmo (Román Rodríguez, 2001), Dianium (Fig. 2), (Gisbert y Sentí, 1989) e Ilerda (Lorencio et alii, 1998)-.

\section{3. EL SIGLO III. LA ENTRADA EN ESCENA DE} NUEVOS PROTAGONISTAS

Desde la tercera centuria, especialmente a partir de su segunda mitad, los signos de continuidad respecto al Alto Imperio van a ser cada vez mas escasos, destacando la Constitutio de Diocleciano y Maximiano -Cod. Iust. 3, 44, 12 (290 d.C.)-, que no aporta nada nuevo respecto a lo expuesto en leyes anteriores (Fernández Fernández, 1989, 83).

Por el contrario, vamos a asistir al arranque de diversos cambios en el suburbium que, a corto y medio plazo (siglos IV y V), tendrán un gran impacto en la superficie in urbe:

a) La movilidad y descentralización de las áreas cementeriales. A partir del siglo III d.C. se ha detectado (Cantino y Lambert, 1998; Sánchez Ramos, 2006 vol. II, 376 ss.; Gurt y Sánchez, 2010) la continuidad de las áreas cementeriales herederas del Alto Imperio, pero también la aparición de necrópolis -de dimensiones variables- en espacios libres, o cuya función previa era doméstica y/o artesanal.

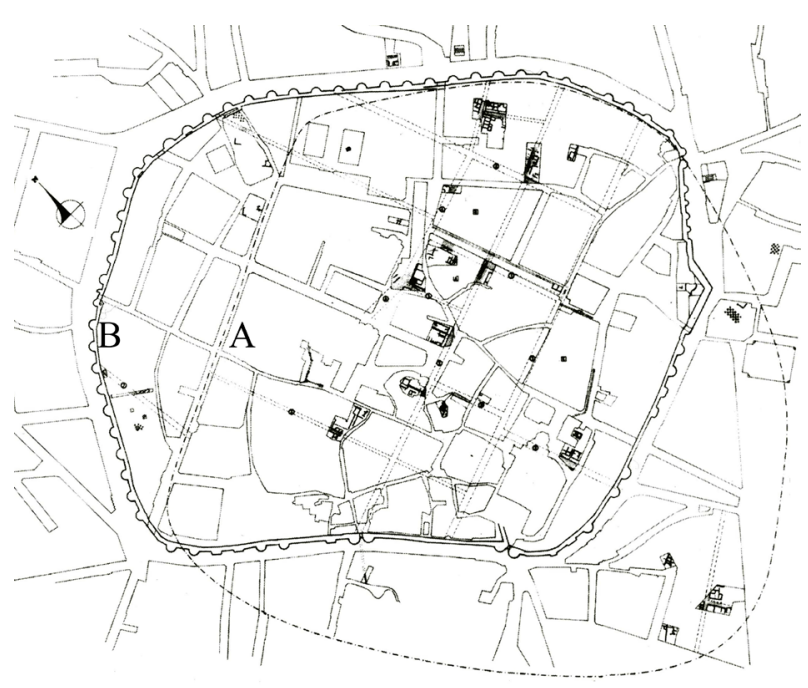

Fig. 3. Lucus Augusti. Perímetro amurallado en el Alto Imperio (A) y en el Bajo Imperio (B). Modificado a partir de González Fernández y Carreño, 1999, 1178.

Estas modificaciones topográficas se han puesto en conexión -entre otros factores- con un abandono temporal de los suburbios, una reforma o construcción ex novo de los recintos amurallados, y un traslado de la mayor parte de la población hacia el interior de las ciudades. En este sentido, ocasional- 
mente, los nuevos recintos defensivos no respetaron el trayecto de las viejas defensas ${ }^{11}$ (Fig. 3). Como consecuencia, la erección de las nuevas murallas implicó un cambio en el recorrido de los antiguos pomeria, cuyo trazado se readaptó al impuesto por las infraestructuras militares recién erigidas, ya que nos encontramos en un momento (siglo III y parte del IV) caracterizado por la vigencia y el funcionamiento -en la mayor parte de las urbes romanas- de la antigua línea de separación entre el mundo de los vivos y el de los muertos.

Precisamente, el refuerzo o construcción ex novo de las defensas -iniciado a partir del tercer cuarto de la tercera centuria debido al contexto de inestabilidad existente (Brogiolo, 2011, 89)- influyó en nuestro objeto de estudio, al ser muy frecuente la utilización -como materia prima- de materiales arquitectónicos procedentes de tumbas y monumentos funerarios previos de diversa índole, lo que según G. Cantino y C. Lambert $(1998,103)$ representa "un rottura degli equilibri tradizionali, tanto sotto il profilo pratico che nelle prospettive mentali”, al cuestionarse -de forma más intensa que en épocas anteriores- la inviolabilidad de las áreas funerarias.

Tampoco podemos olvidar el arranque de un complejo y desigual proceso de aproximación espacial de los coementeria suburbanos hacia las murallas de las ciudades, caracterizado por ser progresivo pero discontinuo al haberse identificado, a una considerable distancia de la urbs, necrópolis activas durante toda la Antigüedad Tardía. Según G. Cantino y Ch. M $M^{a}$ Lambert $(1998,103)$, no podemos recurrir a explicaciones como "fattore distanza e delle sue implicazioni pratiche, quali la facilità di acceso o la sicurezza" a la hora de entender este movimiento centrípeto, considerado en muchos casos un paso previo a la ruptura funeraria del pomerium (Cantino y Lambert, 1998, 103).

b) La convivencia entre vivos y muertos en el suburbio no sólo continuó en estas centurias, sino que se intensifican los testimonios, al encontrarnos con un variado elenco de tumbas situadas a escasos metros de viviendas que seguían estando habitadas ${ }^{12}$.

11 Algunos ejemplos paradigmáticos en la Península Ibérica son Bracara Augusta (Franco Ribeiro, 2008, 264), Lucus Augusti (Fernández Ochoa et alii, 2005, 99), datados en época tetrárquica; o Termes (Argente y Díaz, 1996, 156-157), en la segunda mitad del siglo III d.C.

12 Por citar sólo tres ejemplos de las capitales de provincia hispanas, podemos incluir los testimonios funerarios identifica- c) La cristianización de los suburbia. El hábito de sepelir a los difuntos lo más cerca posible de un lugar relacionado de forma directa o indirecta con la memoria de un mártir y/o santo se documenta con claridad a partir del siglo III d.C., adquiriendo un notable auge en las siguiente centuria, cuando se extendió una idea según la cual la proximidad espacial favorecía la protección espiritual de los difuntos, dando lugar al fenómeno conocido como tumulatio ad sanctos (Ripoll, 1999, 250; Godoy, 2005).

Inicialmente, los santos, mártires y aquellos individuos de notable importancia dentro de la comunidad cristiana (p.e., altos cargos eclesiásticos) fueron inhumados extra urbem, según quedaba dictado en las leyes romanas -todavía vigentes-; por tanto, no debe extrañarnos que los primeros santuarios martiriales surgieran en el suburbio, donde se han constatado dos modalidades: los primarios -escenarios directos de la pasión o del sepelio de los mártires y/o confesores-, y los secundarios -creados a partir de las reliquias a contactu- ${ }^{13}$ (Godoy, 2005, 64).

Desde fechas muy tempranas ambos se rodearon de enterramientos debido a su importante poder de atracción, si bien, los cambios más importantes tuvieron lugar a partir del edicto de Milán (313), pues desde entonces los hitos suburbanos cristianos fueron sometidos a una progresiva monumentalización ${ }^{14}$ que incluyó la construcción de memoriael martyria y su posterior transformación en imponentes basílicas cristianas (Sánchez Ramos, 2006, 378-379; Gurt y Sánchez, 2010, 476 ss.).

La gestión, el servicio y la administración de los inmuebles sacros recayeron en comunidades de clérigos, quienes residían junto a las basílicas y las áreas funerarias, dando lugar frecuentemente a auténticos vici (Treffort, 1996, 57). El resultado fue una coexistencia aún más estrecha entre el mundo de los vivos y el de los difuntos que, según $\mathrm{H}$. Galinié (1996, 19), fue decisiva a la hora de anular el pomerium puesto que "des vivants vont aux morts, après deux siècles de contacts de plus en plus

dos en la "Manzana de Banesto", en Corduba -siglo IV- (Salinas Villegas, 2005; Sánchez Ramos, 2006, 293); la domus “del anfiteatro" en Emerita Augusta -siglo III- (Bejarano, 2004, 253) o la parcela 31 PERI 2 en Tarraco-siglos IV y V- (Gurt y Macías, 2002, 94; López Vilar, 2006, 251).

13 Es decir, trozos de ropa, óleos, agua, tierra, ampullae, lámparas, etc., sometidos a un contacto directo con los mártires.

14 Este proceso generalmente arrancó en las postrimerías de la cuarta centuria, salvo en capitales imperiales como Roma, Mediolanum y Ravenna, donde se inició a comienzos de la misma (López Quiroga y Martínez, 2009, 152). 


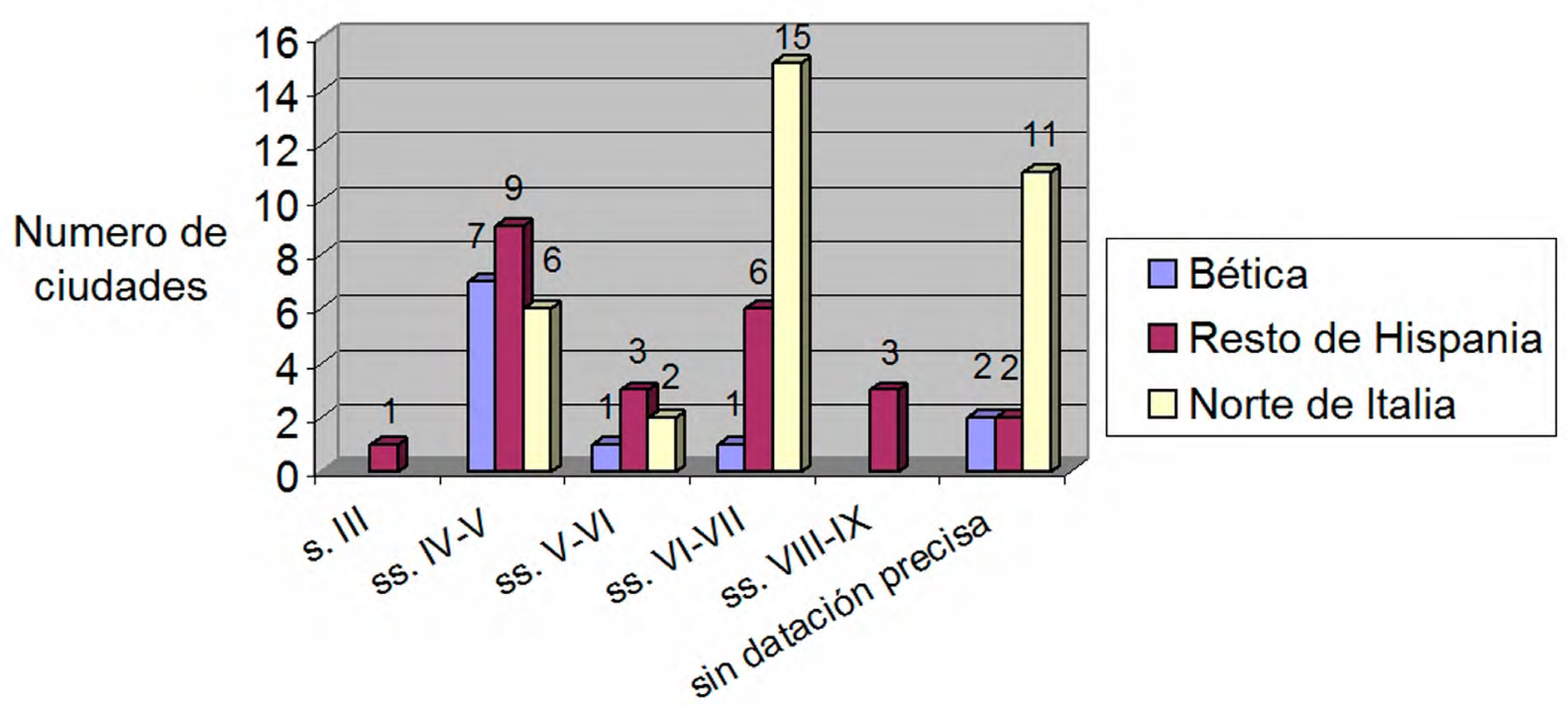

Fig. 4. Mediterráneo Occidental. Cronología de la ruptura funeraria del pomerium en 69 ciudades. Elaboración propia

étroits, dans les basiliques funéraires et à leur entour immédiat".

A pesar de estas importantes novedades, lo cierto es que durante la tercera centuria el pomerium siguió siendo una línea respetada y que continuaba vetando -con una efectividad bastante similar a la del Alto Imperio- el mundo funerario dentro de la superficie in urbe; de hecho, para este siglo sólo se ha podido individualizar un núcleo urbano (Carthago Nova) con sepulturas intra moenia (Fig. 4). Dicho ejemplo es muy llamativo ${ }^{15}$ al haberse contabilizado hasta la fecha tres sepulturas datadas en la tercera centuria: dos en los aditus del antiguo teatro (Ramallo y Vizcaíno, 2007, 511) y otra junto al Augusteum (Ramallo et alii, 2010, 235).

Las tres se insertan en una coyuntura caracterizada por una contracción desde el siglo II d.C. de la superficie habitada; un abandono y amortización de los edificios e infraestructuras públicas; una colmatación de las áreas portuarias y, por último, una "mayor permeabilidad de los muros ciudadanos, antes infranqueables" dando lugar a "una mayor vinculación, sino plena identidad, entre las zonas urbana y suburbana" (Ramallo et alii, 2010, 233-235).

\section{4. Los SIGLOS IV y V. EL MOMENTO CLAVE}

Si tenemos en cuenta que desde momentos tardorrepublicanos y altoimperiales -en especial a par-

15 Sin parangón (que sepamos) con otros asentamientos del Occidente Europeo. tir del siglo III d.C.- se fue gestando un panorama favorable y propenso de cara a un quebrantamiento funerario generalizado del pomerium (al margen de las excepciones permitidas por la ley), no nos debe extrañar que tanto los testimonios escritos como los arqueológicos reflejen una clara y evidente ruptura respecto a las centurias anteriores.

Desde un punto de vista legislativo debemos hacer referencia al Codex Theodosianus, lib. IX, tit. XVII, lex 6 (a. 381 d.C.) y $\operatorname{lex} 7$ (a. 386 d.C.). El texto, redactado en Constantinopla, nos muestra el panorama existente -como mínimo- en la parte oriental del Imperio, siendo de gran importancia para el tema que nos interesa por dos motivos. En primer lugar, porque ordena el desmantelamiento y traslado extra urbem de todas las estructuras funerarias que obstruyesen el espacio situado por encima del subsuelo y penaliza la transferencia de reliquias de santos al interior de la ciudad (Lambert, 1997, 287), lo que evidencia la existencia de santuarios martiriales in urbe dotados de inhumaciones ${ }^{16}$. En segundo, se trata de la última ley que prohíbe -de forma expresa- las tumbas en el interior del pomerio, ya que con posterioridad no contamos con norma jurídica alguna (civil o sacra) que castigue esta

16 A pesar de ser un ejemplo que parece entroncar con el privilegio concedido a los clari viri (vid. supra), conviene aludir al mausoleo construido por el emperador Constantino $(\dagger$ 337 d.C.), en el interior del recinto amurallado de Constantinopla y que sirvió como lugar de sepultura de varios emperadores (Chavarría, 2009, 188). 


\begin{tabular}{|c|c|c|}
\hline Asentamiento & Cronología & Bibliografía \\
\hline Arunda & s. V & (Carrillero y Nieto, 1995) \\
\hline Astigi & s. V & (García-Dils et alii, 2005, 261 y 263; 2011, 269) \\
\hline Aurgi & Post. $1^{\text {a }}$ mitad del s. V & (Serrano, 2004, 93-94) \\
\hline Auria & $2^{\text {a }}$ mitad del s. VI - s. VII & (López Quiroga y Rodríguez, 1999, 1402) \\
\hline Baelo Claudia & Ss. V-VI & (Sillières, 1997, 197; Arévalo et alii, 2006, 68-69) \\
\hline Baetulo & ss. V-VI & (Padrós, 1999, 90) \\
\hline Barcino & s. IV o finales del s. VI & (Puig Verdaguer, 1999, 267; Beltrán de Heredia, 2008a, 246) \\
\hline Bracara Augusta & ¿Ss. V-VI? & (Franco Ribeiro, 2008, 300-303) \\
\hline Carteia & s. VI "avanzado" - s. VII & (Bernal, 2006, 462) \\
\hline Carthago Nova & s. III & (Ramallo y Vizcaíno, 2007, 511; Ramallo et alii, 2010, 235) \\
\hline Corduba & ss. IV-V & $\begin{array}{l}\text { (Hidalgo, 1993, 109; Molina Expósito, 2003, 44-47; Vargas Cantos, } \\
\text { 2005, 12-13) }\end{array}$ \\
\hline Clunia & $2^{\mathrm{a}}$ mitad del s. IV - s. V & (Palol 1991-1978, 300; 1994, 75-76) \\
\hline Emerita Augusta & s. V & (Alba, 1998, 370) \\
\hline Emporiae & $2^{a}$ mitad del s. VI & (Aquilué, 2008, 104) \\
\hline Gades & "hispano-visigoda" & (Bernal y Lagóstena, 2010, 423) \\
\hline Hispalis & $2^{\text {a }}$ mitad del s. V & (Amores y González Acuña, 2006, 202; González Acuña, 2011, 533) \\
\hline Iesso & s. IV- $1^{\text {a }}$ mitad del s. V & (Pera Isern, 1999, 271-272; Pera Isern y Uscatescu, 2007, 241) \\
\hline Ilerda & "bajoimperial” ¿ss. IV-V? & (Gil Gabernet et alii, 2001, 167) \\
\hline Iliberris & $1^{\text {a }}$ mitad del s. V & (Pérez Rodríguez-Aragón, 1997, 641-642) \\
\hline Ilunum & s. VII & (López Quiroga, 2010, 317-319) \\
\hline Iluro & ss. IV-V & (Revilla y Cela, 2006, 99) \\
\hline Lucus Augusti & ss. IV-V & (López Quiroga y Rodríguez, 1999, 1396) \\
\hline Malaca & $1^{\mathrm{a}}$ mitad del s. V & (Pérez Rodríguez-Aragón, 1997, 641-642; Corrales, 2007, 74) \\
\hline Munigua & Principios del s. IV & (Schattner et alii, 2006, 73; Eger, 2006, 144) \\
\hline Pollentia & Desde el 600 d.C. & (Riera et alii, 1999,343 ) \\
\hline Rhode & ss. IV & (Nolla, 1997, 139; Puig Griessenberger, 1999) \\
\hline Tarraco & ss. V-VI & (Macías et alii, 2007, 57) \\
\hline Termes & Finales del s. VI & (Gutiérrez Dohijo, 2007, 157) \\
\hline Valentia & 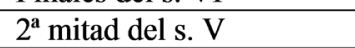 & (Alapont y Ribera, 2009, 61) \\
\hline Veleia & ss. IV-V & (Filloy et alii, 1991, 250; Filloy y Gil 2007, 473-478) \\
\hline Verurium & $2^{\mathrm{a}}$ mitad del s. VII & (Pedro y Inês, 1995, 345) \\
\hline
\end{tabular}

Fig. 5. Hispania. Cronología de la ruptura funeraria del pomerium en las ciudades analizadas. Elaboración propia.

costumbre. Para G. Cantino Wathagin $(1999,157)$, sorprende dicha «excepcionalidad», en especial si la comparamos con la profusa legislación tardoantigua en ámbitos tan diversos como el traslado de reliquias, la reutilización de material constructivo y decorativo (spolia) o la supresión de los sacrificios paganos, lo que evidencia "a scant interest in the matter" (Cantino, 1999, 157) por parte de las autoridades a la hora de impedir esta práctica funeraria.

De hecho, apenas unas décadas más tarde, el emperador León I (457-474 d.C.) promulgó una disposición que para C. Citter $(1997,28)$ y J. Sales Carbonell $(2003,322)$ constituye la primera medida legislativa que permite inhumar dentro de la urbs (de Constantinopla); no obstante, "se desconoce el alcance e influencia que esta disposición imperial tuvo en la parte occidental del imperio y más concretamente, en Hispania" (Sales 2003, 322).
La pérdida del significado y función original del pomerium también se observa en la utilización del término por parte de varios autores de la segunda mitad del siglo IV e inicios del $\mathrm{V}$, quienes emplearon dicha palabra con el significado genérico de límite, sin ningún contenido sacro o ritual. Entre los ejemplos (Annibaletto, 2010, 154-155), tenemos a Amiano Marcelino ${ }^{17}$ ("borde del camino/carretera"), Macrobio ${ }^{18}$ ("límite figurativo"), San Jerónimo ${ }^{19}$ ("huerto dotado de una domus, vinea y hortus" o "jardín perteneciente a la casa de una persona acomodada y cercado por un muro"), y ya en el siglo VI, Jordanes ${ }^{20}$ ("confín territorial”). En

17 Rerum gestarum libri XXXI, 25, 10, 5. (Annibaletto, 2010, 154-155).

18 Saturnalia, 1, 24, 12. (Idem).

19 Vulgata. eccles. 2,4-5 y Vulgata. Dan. 13,4; 13,7; 13, 15-20; 13, 26, 13; 36-38. (Idem).

20 Getica. 199. (Idem). 
la pérdida de su acepción inicial debieron influir, entre otros factores, la cristianización de la cultura, la decadencia de los collegia augurales a partir de la segunda mitad del siglo IV d.C. o la propia tradición manuscrita (Annibaletto, 2010, 155).

Por su parte, los testimonios arqueológicos confirman lo expuesto con anterioridad, ya que disponemos de varios yacimientos cuyo límite sacro se quebrantó desde un punto de vista funerario (y sin tener en cuenta las citadas excepciones legales) en pleno siglo IV d.C. En Hispania contamos con los asentamientos de Munigua (inicios de la cuarta centuria), Rhode y quizás Barcino ${ }^{21}$, mientras que fuera de la Península Ibérica podemos incluir la necrópolis de la segunda mitad del siglo IV en la ciudad argelina de Sitifis (Sánchez Ramos, 2006, 383), o los ejemplos italianos de Módena y Rímini (Baldini, 2003, 180; Ortalli, 2003, 113-114). En cualquier caso, conviene tener en cuenta que los enterramientos in urbe de estos núcleos urbanos no parecen responder a una misma casuística, ya que las tumbas de Rímini y probablemente las de Munigua, se relacionan con establecimientos residenciales y/o productivos, mientras que en Rhode -y quizás en Barcino- parecen estar conectadas con construcciones cristianas.

Mucho más frecuentes son las ciudades cuyo pomerium se anuló en un momento impreciso de la cuarta y quinta centuria (Fig. 5), o bien, en esta última; se trata de una dinámica registrada claramente en Baetica (6 yacimientos sobre un total de 11), y en menor medida en el resto de la Península Ibérica (8 ó 9 sobre un total de 24).

Precisamente, en el siglo V d.C. destacamos la entrada en escena de las "invasiones bárbaras" y de la inestabilidad político-militar derivada de éstas, un nuevo protagonista que pudo favorecer la presencia de inhumaciones intra moenia. Este factor se ha considerado especialmente determinante en Roma (Meneghini y Santageli, 2004, 124-125) o en Emerita Augusta (Alba, 1998, 370; 2005,

21 En Barcelona se tiene conocimiento de un sepulcro vinculado con un hipotético edificio sacro y datado, con las cautelas necesarias, "al voltant del segle IV" según los fragmentos de lucerna encontrados junto a la tumba (Puig Verdaguer, 1999, 267). Un argumento indirecto a favor de esta cronología vendría confirmado por el hallazgo, en el entorno de la tumba, de un fragmento de inscripción funeraria del siglo $\mathrm{V}$ y un sello (de similar cronología) con la leyenda Petrus Paulus, interpretado como "un sello para marcar el pan litúrgico" (Beltrán de Heredia, 2008a, 252-253).
131), -donde, a raiz de los asedios a los que fueron sometidos ambas ciudades, hubo dificultades a la hora de enterrar a los difuntos en el suburbio-, pero tampoco podemos descartar su influencia en otros antiguos municipia hispanos como Iliberris y Malaca, donde curiosamente las inhumaciones in urbe más antiguas se datan en la primera mitad de la quinta centuria gracias a los objetos hallados en su interior. Ajuares que, para F. Pérez RodríguezAragón (1997, 641), se "podrían relacionar con la presencia en suelo hispánico de vándalos y alanos". No obstante, el impacto de las invasiones en la topografía urbana -incluyendo la funeraria- sigue siendo una cuestión sometida a intenso debate, al contabilizarse núcleos urbanos donde la anulación del pomerio tuvo lugar antes o después del siglo $\mathrm{V}$. Además, no todas las ciudades sufrieron el mismo nivel de inseguridad y, de hecho, encontramos estructuras funerarias intra moenia "even in cities untouched by the disruptions of war" (Cantino Wataghin, 1999, 14).

Asimismo, a lo largo del s. IV y, sobre todo, en el V d.C. (Mateos, 2005, 55-58), no podemos olvidar el arranque de la cristianización de la topografía in urbe. Un proceso que supuso, entre otras transformaciones, la aparición de diversos inmuebles eclesiásticos (en especial los complejos episcopales $^{22}$ ) que gracias a la tumulatio ad sanctos y a las reliquias a contactu (vid. supra), favorecieron la conformación de áreas cementeriales (Godoy, 2005, 66-69), pero cuyo verdadero desarrollo $\mathrm{y}$ auge se produjo a partir del siglo VI (Brogiolo, 2011, 144). No obstante, en la actualidad tampoco se descarta (Gurt y Sánchez, 2010, 24) que en realidad, determinadas necrópolis in urbe, favoreciesen a su vez la instalación de edificios sacros como la propia Ecclesia Mater.

Frente a lo expuesto en la Península Ibérica, en otras regiones del Occidente Europeo como la Italia Annonaria nos encontramos ante una situación algo diferente, ya que el pomerium sólo se quebrantó, aparentemente, en unos pocos asentamientos durante la cuarta y la quinta centuria (Brogiolo, 2011, 139). Así, de los 34 núcleos urbanos estudiados sólo $6^{23}$ se vieron afectados por

22 El 95\% de los conjuntos episcopales del Occidente Romano se emplazaron dentro del pomerium (Arbeiter, 2010, 419).

23 Albenga, Aquileia, Ivrea, Modena, Ravenna y Rímini (Baldini, 2003, 180; Lambert, 2003, 230). A ellos podríamos sumar otros ejemplos aislados identificados en el resto de la $\mathrm{Pe}-$ 


\begin{tabular}{|c|c|c|c|c|}
\hline $\begin{array}{r}\text { civitates, } \\
\text { sedi episcopali }\end{array}$ & $\begin{array}{l}\frac{9}{\pi} \\
\frac{\pi}{0} \\
\text { in } \\
\text { in }\end{array}$ & 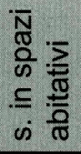 & 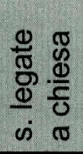 & $\begin{array}{l}\text { datazione } \\
\text { (secoli } \\
\text { d. C.) }\end{array}$ \\
\hline \multirow[t]{2}{*}{ Acqui } & $x$ & 一 & 一 & IV-VI? \\
\hline & - & 一 & $x$ & $?$ \\
\hline \multirow[t]{2}{*}{ Alba } & - & 一 & $?$ & $\mathrm{~V}-\mathrm{VI}$ \\
\hline & - & $x$ & - & $V-V I I$ \\
\hline \multirow[t]{2}{*}{ Albenga } & - & $?$ & - & V \\
\hline & - & - & $x$ & VII-IX \\
\hline Aquileia & - & $x$ & $x$ & $?$ \\
\hline Bergamo & $?$ & - & 一 & $?$ \\
\hline Bologna & $x$ & $x$ & $x$ & $?$ \\
\hline \multirow[t]{2}{*}{ Brescia } & $x$ & $x$ & - & VII \\
\hline & - & - & $x$ & VIII \\
\hline \multirow[t]{2}{*}{ Classe } & - & 一 & $x$ & VI \\
\hline & $x$ & $x$ & - & VII \\
\hline Concordia & $?$ & $x$ & - & $?$ \\
\hline \multirow[t]{2}{*}{ Cremona } & $x$ & $x$ & - & IV $-\mathrm{V}$ \\
\hline & - & - & $x$ & VII \\
\hline Faenza & $x$ & $x$ & - & $?$ \\
\hline Forlimpopoli & - & - & $x^{*}$ & VI \\
\hline Genova & - & 一 & $x$ & $\mathrm{~V}-\mathrm{VI}$ \\
\hline Imola & $x$ & 一 & $x$ & ta/am \\
\hline Ivrea & - & 一 & $?^{*}$ & V \\
\hline Lodi & - & 一 & $?^{*}$ & VI \\
\hline \multirow[t]{3}{*}{ Luni } & $x$ & $x$ & $x$ & VII-XIII \\
\hline & - & - & $x$ & VIII-XII \\
\hline & - & 一 & $?^{*}$ & t.a.q.n. VI \\
\hline
\end{tabular}

\begin{tabular}{|r|c|c|c|l|} 
Milano & - & - & $\mathrm{x}$ & $\mathrm{V}-\mathrm{VII}$ \\
Modena & $\mathrm{x}$ & $\mathrm{x}$ & - & $\mathrm{IV}-\mathrm{V}$ \\
& - & - & $?$ & $\mathrm{VI}$ \\
Padova & $?$ & - & $?^{*}$ & $\mathrm{VI}$ \\
Parma & $\mathrm{x}$ & - & - & $?$ \\
Pavia & - & - & $?$ & $\mathrm{VI}$ \\
Piacenza & $\mathrm{x}$ & - & $\mathrm{x}$ & $\mathrm{VI}$ \\
Ravenna & $\mathrm{x}$ & $\mathrm{x}$ & $\mathrm{x}$ & $\mathrm{VI}$ \\
Reggio Em. & $\mathrm{x}$ & $\mathrm{x}$ & - & ta/am \\
Rimini & $\mathrm{x}$ & $\mathrm{x}$ & $\mathrm{x}$ & t.a.q.n. VI \\
Torino & - & - & $\mathrm{x}^{*}$ & t.a.q.n. VI \\
Tortona & - & - & $\mathrm{x}^{*}$ & $\mathrm{VI} / \mathrm{VII}$ \\
Trento & - & $\mathrm{x}$ & - & $\mathrm{VI}$ \\
VI-VII \\
Ventimiglia & $\mathrm{x}$ & - & - & $\mathrm{VII}$ \\
Vercelli & - & - & - & $\mathrm{VI}-\mathrm{VII}$ \\
Verona & $\mathrm{x}$ & $\mathrm{x}$ & - & VII \\
Vicenza & $\mathrm{x}$ & $?$ & - & $\mathrm{V}$ \\
Zuglio & - & - & $\mathrm{x}$ & $\mathrm{el}$ \\
\hline
\end{tabular}

Tabella I Il rapporto tra spazi abitativi e sepolture in Italia settentrionale. Nessuna attestazione nelle sedi episcopali di Aosta, Asti, Cesena, Como, Feltre, Forli, Novara e Trieste.

Legenda: $s .=$ sepolture; $*$ attestate da epigrafe/i;

t.a.q. n. = terminus ante quem non; $\mathrm{ta} / \mathrm{am}=$ tardoantica/ altomedievale; el = epoca longobarda.

Fig. 6. Italia Annonaria. Tabla elaborada por Ch. M. ${ }^{a}$ Lambert $(2003,230)$ donde resume el quebrantamiento funerario del pomerium en el Norte de Italia durante la Antigüedad Tardía.

enterramientos in urbe durante los siglos IV-V (Fig. 6).

\section{5. SigLOS VI-VII D.C. GENERALIZACIÓN DE LA RUPTURA}

Si avanzamos en el tiempo, nos situamos en una etapa con escasos aunque útiles testimonios escritos que reflejan una plena aceptación de las sepulturas in urbe. El ejemplo más significativo es el canon XVIII del Concilio de Braga I (561 d.C.), estudiado en profundidad por J. López Quiroga y A. M. Martínez Tejera $(2009,155)$, quienes deducen del mismo que "en algunas ciudades del convento bracarense estaba permitido el enterramiento intramuros" con anterioridad al año 561. Según dichos investigadores, el objetivo principal de esta normativa fue fre-

nínsula Italiana, caso de Ascoli (Capelli, 1997, 81-86), Florentia, Lucca (Costantini, 2010-2011, 189) y Roma (Meneghini y Santangeli, 2004, 123). nar y vetar la transformación del espacio interior de las iglesias urbanas en áreas cementeriales (una práctica tolerada en las suburbanas), recurriéndose a la antigua legislación romana para alcanzar dicho $\mathrm{fin}^{24}$.

En cuanto a la pérdida del significado inicial del término pomerio, la tendencia iniciada en la segunda mitad del siglo IV d.C. llegó a su punto culminante en la séptima centuria, cuando, debido a la confusión en la transcripción de los textos de una generación a otra, varios glosadores latinos y griegos utilizaron de forma indistinta dos vocablos con significados iniciales diferentes ${ }^{25}$ (Annibaletto,

24 "Impedir que los restos de los difuntos reposasen en el interior de los templos de la misma forma algunas leyes romanas [...] impedían los enterramientos en el espacio urbano delimitado por las murallas” (López Quiroga y Martínez, 2009, 159).

25 Se trata de pomerium y pomarium, término que alude a aquellas áreas verdes destinadas al cultivo de frutales. 
2010, 155). Por tanto, a partir de los siglos VI-VII d.C., -aunque posiblemente antes-, ya no tiene sentido alguno hablar de pomerium, puesto que ya no existe como tal al haber desaparecido definitivamente el límite que estructuraba la ciudad y que separaba un espacio dedicado en exclusiva a los vivos de otro donde convivían con los fallecidos. En estos momentos, en los que ya no existe la ciudad "romana”, el nuevo paisaje urbano presentará un carácter policéntrico, al estar articulado mediante diversos enclaves -ubicados dentro o fuera de la muralla- y comunicados entre sí mediante una liturgia estacional (Gurt y Sánchez, 2008, 191 ss.; 2010, 493 ss.).

Otras fuentes escritas también han permitido rastrear para estos momentos el cambio en la mentalidad de la población respecto a los enterramientos in urbe. Un ejemplo paradigmático es el del obispo y santo Gastón de Arrás, fallecido en la década de 540 d.C., quien rechazó descansar dentro de los muros del asentamiento, optando por un pequeño oratorio suburbano; empero, apenas un siglo más tarde (645 d.C.), se consideró indigno el lugar, siendo su cuerpo trasladado al interior de la catedral, erigida en plena urbs (Treffort, 1996, 56).

En relación a los testimonios arqueológicos, la información disponible para la Península Ibérica refleja un notable descenso en el número de asentamientos cuyo pomerium se quebrantó por primera vez en la sexta y séptima centuria, una tendencia a la baja especialmente llamativa en Baetica, donde para el período comprendido entre los siglos VI y VII, solo contamos con un único ejemplo seguro (Carteia). En el resto de la Península Ibérica la cifra es algo superior ( 6 sobre un total de 24 ), aunque sigue siendo minoritaria respecto a los siglos IV y V (8 ó 9 ciudades) o V y VI (3 yacimientos). Por el contrario, en la Italia Annonaria las investigaciones $^{26}$ han relevado que dicha práctica funeraria parece "affermarsi solo nel sesto e settimo secolo" (Lambert 2003, 229), pues en más de la mitad de los núcleos estudiados (15 de un total de 34) las sepulturas intra moenia no se datan hasta la sexta y séptima centuria (Fig. $6^{27}$ ).

26 Destacan los estudios a nivel regional de Ch. M. ${ }^{a}$ Lambert $(1997 ; 2003)$, pero también investigaciones locales como las realizadas, entre otros lugares, en Brescia (Brogiolo 1997; 2011, 140-143) o Roma (Meneghini y Santangeli-Valenzani, $1993 ; 2004$

27 Las recientes investigaciones en Módena y Rímini sitúan en el inicio de las sepulturas in urbe en pleno siglo IV (Baldini, 2003, 180; Ortalli, 2003, 113-114).
En cualquier caso, en ambas regiones es evidente que a lo largo de estos dos siglos se detecta un notable incremento en el número total de sepulturas intra moenia -tanto a nivel local, como de la provincia-, lo que refleja la consolidación de esta práctica. Así, en la Bética, frente a 4 tumbas datadas en los siglos IV o IV-V, tenemos 13 para los siglos $\mathrm{V}$ o V-VI, y por último unas 25 (71 si incluimos las de Cartei $^{28}$ ) adscribibles a los siglos VI o VI-VII.

En el resto de la Península Ibérica, pero también en otras ciudades italianas, encontramos una tendencia similar, al haberse constatado en Valentia 59 sepulcros de la sexta, séptima e inicios de la octava centuria (Ribera y Soriano 1987: 153 y 162; Ribera y Rosselló 2000, 163; Alapont y Ribera, 2009) -frente a 29 tumbas datadas desde mediados del siglo V hasta mediados del VI-; en Barcino 35 de la sexta y séptima (Beltrán de Heredia 2008a, 251; 2008b, 280) -frente a una sola adscrita, y con dudas, al siglo IV-, o en Roma, donde se pasó de 7 emplazamientos con estructuras funerarias de los siglos V o V-VI, a 21 de los siglos VI, VI-VII o VII (Meneghini y Santangeli, 1993; 2004, 124).

\section{6. SigLO VIII EN ADELANTE. HACIA UNA NUE-} VA REALIDAD

En el siglo VIII se ha datado el arranque formal de un fenómeno conocido como "cristianización de la muerte" ${ }^{29}$, cuyo triunfo definitivo se sitúa en el s. XII, y que supuso la conversión de los cementerios parroquiales -o episcopales- en el único lugar idóneo donde recibir sepultura (Treffort, 1996, 6061). Estos inmuebles se situaban, en su mayor parte, dentro de los recintos amurallados, lo que favoreció un incremento en el número de las sepulturas in urbe y un paulatino descenso de aquéllas practicadas en el suburbio.

Según A. Azkarate $(2002,136)$, hasta los siglos VIII-IX d.C. la Iglesia no tuvo especial interés en regular determinados hábitos o costumbres relacionados con la muerte (como por ejemplo el lugar de descanso final de los difuntos). Sin embargo, a partir de dicho momento la situación cambió de forma radical debido a: una nueva concepción de la

28 Las tumbas de Carteia han sido excluidas de las estadísticas totales ya que su elevado número sobre la muestra total de inhumaciones intra moenia béticas identificadas (46 de un total de 164), podría distorsionar las estadísticas.

29 Entendida como "su apropiación por parte de la Iglesia" (Azkarate, 2002, 129) 
sepultura y de los ritos funerarios ${ }^{30}$. La consolidación de la red parroquial, convirtiéndose ésta en el elemento de referencia durante la vida (y muerte) de los fieles ${ }^{31}$; la desaparición de una gestión privada del momento del fallecimiento, basada en la fortaleza del derecho familiar y privado; $y$, por último, el establecimiento de nuevas relaciones socioeconómicas características de un contexto feudal, del que los muertos no permanecieron al margen (Treffort, 1996, 59-60; Cantino y Lambert, 1998, 107-108; Chavarría, 2009, 185-188).

Este prolongado proceso se interrumpió o adquirió nuevas características en algunas regiones del Mediterráneo Occidental (incluyendo gran parte de la Península Ibérica), debido al inicio de una nueva coyuntura histórica caracterizada por la islamización de la sociedad. La principal consecuencia será la mayoritaria localización de las áreas funerarias en el suburbio; circunstancia que se explica (León Muñoz y Casal, 2010, 651-653) más por cuestiones prácticas que de otra índole (culturales o jurídicas).

\section{REFLEXIONES FINALES}

Pese al establecimiento y codificación -desde fechas muy tempranas- de una clara diferenciación entre un mundo dedicado en exclusiva a los vivos, y otro en el que éstos podían convivir con otro tipo de actividades, lo cierto es que, desde un primer momento, nunca se logró una efectiva y total exclusión del mundo funerario. Así, las propias singularidades permitidas por la legislación, junto a las repetidas alusiones en las que se prohibían los enterramientos dentro del pomerium, reflejan las dificultades a la hora de aplicar una medida legal que para investigadores como F. Casavola fue impuesta por la religión oficial (ius pontificium) y que "no tenía una correspondencia con las ideas de ultratumba, e iba en contra de los intereses de los particulares" (López Melero, 1997, 114). En este sentido, la población aceptaba desde tiempos inmemoriales

30 "Il valore dell'intercessione del santo lascia il passo alle orazioni e, soprattutto, alle celebrazioni eucaristiche, che diventano determinanti per la salvezza dei defunti”. (Chavarría, 2009, 185).

31 Así, el párroco pasó a ser el encargado de la gestión de los sacramentos a los moribundos, de la celebración de una necesaria liturgia conmemorativa, además del responsable a la hora de elegir el sitio de reposo de sus fieles. En este sentido, con la instauración de esta retícula, la domiciliación de todo individuo se basó en la pertenenencia a una parroquia en particular, lo que implicaba a su vez un lugar de inhumación claramente definido (Treffort, 1996, 60). la presencia de familiares difuntos junto o dentro de las casas, por lo que el principal hándicap de los enterramientos in urbe era el "contagio impuro" derivado de la presencia del cadáver. Una contaminación que, sin embargo, se podía contrarrestar mediante diversos rituales (López Melero, 1997, 114), por lo que no fue impedimento suficiente a la hora de prohibir esta larga tradición.

A pesar de lo expuesto, durante varios siglos el pomerium logró excluir -con una efectividad bastante elevada- el mundo funerario al suburbium, tal y como reflejan los limitados testimonios arqueológicos que han podido ser identificados. No obstante, ya desde momentos tardorrepublicanos se constatan una serie de factores (especialmente prolíficos e intensos a partir del siglo III d.C.) que favorecieron una progresiva pérdida de su significado y función original, de modo que, ya en los siglos IV y $\mathrm{V}$ d.C., se detecta -junto a otras transformaciones topográficas propias de la ciudad tardoantiguauna clara ruptura funeraria del pomerio en muchas ciudades de la Península Ibérica, lo que atestigua el fracaso de la citada legislación.

Esta cronología (cuarta y quinta centuria) contrasta con las de otras ciudades hispanas y, sobre todo, con las procedentes de otras regiones europeas como la Italia Annonaria, donde debemos avanzar a los siglos VI-VII d.C. Entre las posibles explicaciones de este amplio marco cronológico podríamos interpretar la citada ruptura del pomerium como síntoma evidente de una "crisis" urbana iniciada en tiempos y modos diferentes -una hipótesis a la que parecen apuntar yacimientos como Carthago Nova o Munigua-; no obstante, en ocasiones la realidad es más compleja y no siempre se conjugan ambos agentes, como en Emporiae ${ }^{32}$ o Barcino $^{33}$. Tampoco el nivel de importancia de la civitas es un criterio fiable, al identificarse enterramientos in urbe en la cuarta o quinta centuria tanto en centros episcopales y políticos (Lucus Au-

32 Entre inicios del siglo II y finales del III d.C. dos de los tres sectores del antiguo municipium (la neapolis y la ciudad romana) se abandonaron. Tan sólo la antigua paliapolis mantuvo el "rango urbano", cuyo recinto amurallado se reforzó en los siglos IV o V (Nolla y Aquilué, 1999, 98), no siendo invadida por enterramientos hasta momentos posteriores al s. VI avanzado (Nolla y Sagrera, 1996, 14; Aquilué, 2008, 104).

33 En Barcelona se ha identificado un sepulcro datado, al parecer, y con la prudencia necesaria, en el siglo IV (vid. supra) es decir, en un momento en el que aún continuaban levantándose pedestales en el foro, al fecharse el más tardío entre los años 379 y 385 (Beltrán de Heredia, 2008b, 281). 
gusti o Corduba), como en otros con un papel más secundario (Clunia, Veleia o Rhode).

Del mismo modo, y atendiendo a factores exógenos, el período de tiempo durante el cual un determinado territorio quedó bajo el control de Roma no se puede emplear como único criterio (al remontarse algunas inhumaciones a los siglos III o IV). Asimismo, la mayor o menor presencia de habitantes de Europa central, oriental o septentrional no parece haber sido un agente decisivo, al igual que el grado de pervivencia del sustrato romano, -según ha constatado Ch. M. ${ }^{a}$ Lambert $(2003,236)$ en la Italia Annonaria-, o el impacto de las "invasiones bárbaras", que obviamente debió variar dependiendo de cada ciudad.

Por tanto, y en vista de la situación, a la hora de explicar la desigual cronología sólo nos queda recurrir a causas "locales" 34 cuyo peso e influencia pudieron variar según cada ciudad, sin poder olvidar tampoco la propiedad aleatoriedad del registro arqueológico.

Si dejamos a un lado la problemática derivada de dicha cronología, es evidente que ya en los siglos VI y VII d.C., los testimonios escritos y arqueológicos impiden que podamos hablar de pomerium con su función y significado original. Dos centurias caracterizadas por el incremento en el número de los enterramientos en el interior de los recintos amurallados aún vigentes, lo que apunta hacia la desaparición definitiva de las barreras físicas y simbólicas entre el espacio urbano y suburbano. Una dinámica que se intensificará aún más desde los siglos VIII y IX d.C., con el triunfo de una modalidad de enterramiento asociada a una iglesia episcopal o parroquial.

\section{BibLIOGRAFÍA}

Alapont Martín, Ll. y Ribera i Lacomba, A. V. (2009), "Topografía y jerarquía funeraria en la Valencia tardoantigua”, en J. López Quiroga y A. M. Martínez (coord.), Morir en el Mediterráneo medieval, Archaeological Studies on Late Antiquity and Early Medieval Europe (400-1000 A. D.), Oxford, 5986.

Alba Calzado, M. (1998), "Consideraciones arqueológicas en torno al siglo $\mathrm{V}$ en Mérida: repercu-

34 Mayor o menor permanencia de antiguas costumbres funerarias; desinterés o imposibilidad por parte de las autoridades a la hora de regular esta práctica; fortaleza del derecho familiar; mayor o menor cristianización de sus habitantes; dinamismo de las áreas cementeriales suburbanas, etc. siones en las viviendas y en la muralla", Memoria 2: Excavaciones arqueológicas en Mérida, 1996, 361-385.

Amores Carredano, F. y González Acuña, D. (2006), "V fase de intervención arqueológica en el mercado de la Encarnación (Sevilla). Contextos tardoantiguos", Anuario Arqueológico de Andalucía /2003, III, 197-206.

Annibaletto, M. (2010), Oltre la città. Il suburbio nel mondo romano, Fondazione A. Colluto, L'album 16, Rubano.

Aquilué Abadías, X. (2008), "Empúries en l'antiguitat tardana. El pas del món antic al món medieval", Annals de l'Institut d'Estudis Empordanesos, 39, 101-113.

Arbeiter, A. (2010), “¿Primitivas sedes episcopales hispánicas en los suburbia? La problemática de cara a las usanzas en el ámbito mediterráneo occidental”, en D. Vaquerizo (ed.), Las áreas suburbanas en la ciudad histórica. Topografía, usos y función, Monografías de Arqueología Cordobesa, 18, Córdoba, 413-434.

Arce Martínez, J. (1990), Funus Imperatorum. Los funerales de los emperadores romanos, Madrid.

Arévalo González, A. et alii. (2006), "El mundo funerario tardorromano en Baelo Claudia. Novedades de las intervenciones arqueológicas del 2005 en la muralla oriental”, Anales de Arqueología Cordobesa, 17, II, 61-84.

Argente Oliver, J. L. y Díaz Díaz, A. (1996), Tiermes, guía del yacimiento y museo, Soria.

Azkarate Garai-Olaun, A. (2002): "De la tardoantigüedad al medievo cristiano. Una mirada a los estudios arqueológicos sobre el mundo funerario", en D. Vaquerizo (ed.), Espacios y usos funerarios en el Occidente romano, Córdoba, 115-140.

Baldini Lippolis, I. (2003), "La fine di domus e palatia. Trasformazioni e cesure attraverso la documentazione archeologica”, en J. Ortalli y M. Heinzelmann (a cura di), Abitare in città. La Cisalpina tra imperio e medioevo, Palilia 12, Wiesbaden, 173-186.

Bejarano Osorio, A. (2004), El Mausoleo del Dintel de los Ríos: los contextos funerarios tardios en Augusta Emerita, Cuadernos Emeritenses, 27, Mérida.

Beltrán de Heredia Bercero, J. (2008a), "Inhumaciones "privilegiadas" intra muros durante la Antigüedad Tardía en Barcino", Anales de Ar- 
queología Cordobesa, 19, 231-260.

(2008b), "Barcino durante la antigüedad tardía", Zona Arqueológica, 9, 273-289.

Bernal Casasola, D. (2006), "Carteia en la Antigüedad Tardía”, en L. Roldán et alii (dir.), Estudio históricoarqueológico de la ciudad de Carteia, (San Roque, Cádiz), 1994-1999, I, Madrid, 417-464.

Bernal Casasola, D. y Lagóstena Gutiérrez, J. (2010), "Muriendo en Gades en la Antigüedad Tardía", en A. M. Niveau y V. Gómez (ed.), Las necrópolis de Cádiz. Apuntes de arqueología gaditana en homenaje a J. F. Sibón Olano, Cádiz, 407-444.

Blasi, M. (2008), "Il caso controverso degli onori funebri per Publio Valerio Publicola", en G. Bartolini y M. G. Benedettini (coord.), Sepolti tra $i$ vivi. Evidenza ed interpretazione di contesti funerari in abitato, Scienze dell'Antichità, Storia, Archeologia, Antropologia 14.2 (20072008), Roma, 1047-1066.

Brogiolo, G. P. (1997), "Le sepolture a Brescia tra tarda antichità e prima età longobarda (ex. IVVII)", en L. Paroli (a cura di), L'Italia centrosettentrionale in età longobarda, Firenze, 413-424.

Brogiolo, G. P. (2011), Le origini della città Medievale, PostClassical Archaeologies/Studies, 1, Mantova.

Cantino Wataghin, G. (1999), "The ideology of urban burials", en G. P. Brogiolo y B. Ward Perkins (ed.), The idea and ideal of the town between Late Antiquity and the Early Middle Ages, Leiden, 147-180.

Cantino Wataghin, G. y Lambert Ch. M. (1998), "Sepolture e città. L'Italia settentrionale tra IV e VIII secolo", en G. P. Brogiolo y G. Cantino (a cura di), Sepolture tra IV e VIII secolo. VII, Mantova, 89-114.

Cappelli, F. (1997), "Le origini della cattedrale di Ascoli. Aspetti di urbanistica altomedievale in una città del Picenum", en L. Paroli (a cura di), L'Italia centrosettentrionale in età longobar$d a$, Firenze, 81-89.

Carafa, P. (2008), "Uccisioni rituali e sacrifici umani nella topografia di Roma", en G. Bartolini y M. G. Benedettini (coord.), Sepolti tra i vivi. Evidenza ed interpretazione di contesti funerari in abitato, Scienze dell'Antichità, Storia, Archeologia, Antropologia, 14.2 (2007-2008), Roma, 667-703.
Carandini, A. (2008), "Uccisioni rituali sacrifici umani a Roma, tra centro protourbano e prima cittàstato. Abbozzando una sintesi”, en G. Bartolini y M. G. Benedettini (coord.), Sepolti tra $i$ vivi. Evidenza ed interpretazione di contesti funerari in abitato, Scienze dell'Antichità, Storia, Archeologia, Antropologia, 14.2 (20072008), Roma, 705-710.

Carrillero Millán, M. y Nieto González, B. (1995), "Aproximación al fenómeno paleocristiano en la depresión natural de Ronda (Málaga)", $I V$ Reunió d'Arqueologia Cristiana Hispànica, Barcelona, 185-191.

Chavarría Arnau, A. (2009), Archeologia delle chiese: dalle origini all'anno mille, Roma.

Citter, C. (1997), "La trasformazione di aree ed edifici pubblici nelle città toscane fra tardoantico e altomedioevo", en S. Gelichi (ed.), Atti del I congresso di Archeologia Medievale, Pisa, 2730.

Corrales Aguilar, M. (2007), "El teatro romano de Málaga: Evolución de un espacio”, Mainake, XXIX, 53-76.

Costantini, A. (2010-2011), "Topografia funeraria e ingresso delle sepolture in urbe nella Toscana tardoantica. I casi di Firenze e Arezzo", Anales de Arqueología Cordobesa, 21/22, 173-196.

Eger, Ch. (2006), "Tumbas de la Antigüedad Tardía en Munigua. Tipos de tumba, ritos de enterramiento y ajuares funerarios en una pequeña ciudad del sur de España en los siglos III/IV a VII", Anales de Arqueología Cordobesa, 17, II, 137-160.

Fernández Fernández, R. M. (1989), "La ley de la Colonia Genetiva Iulia en la experiencia romana sobre comunidades: Urso 73, 74, de las XII Tablas al código de Justiniano”, en J. González Fernández (coord.), Estudios sobre Urso. Colonia Iulia Genetiva, Sevilla, 79-92.

Fernández Ochoa, C. et alii (2006), "La dinámica urbana de las ciudades de la fachada noratlántica y del cuadrante noroeste de Hispania durante el Bajo Imperio y la Antigüedad Tardía (siglos IIIVII d.C.)", VI Reunió d'Arqueologia Cristiana Hispànica, Barcelona, 95-119.

Filloy Nieva, I. y Gil Zubillaga, E. (2007), "Vida cotidiana al abrigo de las murallas. Novedades de la investigación sobre el recinto amurallado tardorromano de Veleia (Iruña de Oca, Álava, País Vasco)", Murallas de Cidades Romanas no Occidente do Impero. Lucus Augusti como 
paradigma, Lugo, 469-480.

Filloy Nieva, I. et alii (1991), "Algunas precisiones en torno a la ciudad romana de Iruña", Cuadernos de Sección de Eusko Ikaskuntza, Prehistoria-Arqueología, 4, 239-263.

Franco Ribeiro, M. ․ C. (2008), Braga entre a época romana e a Idade Moderna. Uma metodologia de análise para a leitura da evolução da paisagem urbana, Tesis Doctoral, Braga.

Galinié, H. (1996), "Le passage de la nécropole au cimetière: les habitants des villes et leurs morts, du début de la christianisation à l`an Mil”, en M. Galinié y E. ZadoraRio (dir.), Archéologie du cimetière chrétien, 11e supplément à la Revue Archéologique du Centre, Tours, 17-22.

García-Dils de la Vega, S. et alii (2005), "La tumba visigoda de Sapatio", Spal, 14, 259277.

García-Dils de la Vega, S. et alii (2011), "La conversión de una porticus monumental de colonia Augusta Firma en recinto funerario cristiano", Habis, 42, 263-291.

Gil Gabernet, I. et alii (2001), "De la Ilirta prerromana a la Ilerda tardorromana. Nuevos datos tras dos décadas de investigación continuada en Lérida”, Archivo Español de Arqueología, 74, 161-181.

Gisbert Santoja, J. A. y Sentí Ribes, M. (1989), "Enterramientos infantiles fundacionales en el "Edificio Horreum" y "Edificio Occidental" del yacimiento romano de Dianium (Denia, Alicante)", Cuadernos de prehistoria y arqueología castellonense, 14, 95-126.

Godoy Fernández, C. (2005), "Les ciutats d'Hispania sota la protecció del sants màrtiris: transformacions del concepte espai religiós entre l' antiguitat tardana i l' edat mitjana", VI Reunió d'Arqueologia Cristiana Hispànica, Barcelona, 63-72.

González Acuña. D. (2011), Forma Urbis Hispalensis. El urbanismo de la ciudad romana de Hispalis a través de los testimonios arqueológicos, Fundación FocusAbengoa, 30 Sevilla.

Gurt Esparraguera, J. M. y Macías Solé, J. M. (2002), "La ciudad y el territorium de Tarraco: el mundo funerario", en D. Vaquerizo (ed.), Espacios y usos funerarios en el Occidente romano, Córdoba, 87-112.

Gurt Esparraguera, J. M. y Sánchez Ramos, I. M. ${ }^{a}$ (2008), "Las ciudades hispanas durante la Anti- güedad Tardía: una lectura arqueológica”, Zona Arqueológica, 9, 183-202.

Gurt Esparraguera, J. M. y Sánchez Ramos, I. M. ${ }^{a}$ (2010), "Topografía funeraria de las ciudades hispanas en los siglos IVVII", Madrider Mitteilungen, 52, 457-513.

Gusberti, E. (2008), "Sepolture in abitato a Roma tra VIII e VII secolo a.C", en G. Bartolini y M. G. Benedettini (coord.), Sepolti tra i vivi. Evidenza ed interpretazione di contesti funerari in abitato, Scienze dell'Antichità, Storia, Archeologia, Antropologia, 14.2 (2007-2008), Roma, 639-651.

Gutiérrez Dohijo, E. (2007), "La necrópolis hispanovisigoda del área foral de Termes", Pyrenae, 38, 1, 129-162.

Hidalgo Prieto, R. (1993), "Nuevos datos sobre el urbanismo de Colonia Patricia Corduba: excavación arqueológica en la calle Ramírez de las Casas-Deza, 13", Anales de Arqueología Cordobesa, 4, 91-134.

Lambert, Ch. M.. (1997), "Le sepolture in urbe nella norma e nella prassi (tarda antichitàalto medioevo)", en L. Paroli (a cura di), L'Italia centrosettentrionale in età longobarda, Firenze, 285-293.

Lambert, Ch. M.a (2003), "Spazi abitativi e sepolture nei contesti urbani", en J. Ortalli y M. Heinzelmann (a cura di), Abitare in città, $L a$ Cisalpina tra imperio e medioevo, Palilia 12, Wiesbaden, 229-239.

León Muñoz, A. y Casal García, M.ª T. (2010), "Los cementerios de Madinat Qurtuba", en D. Vaquerizo y J.F. Murillo (ed.), El anfiteatro romano de Córdoba y su entorno urbano. Análisis arqueológico (ss. I-XIII d.C.), Monografías de Arqueología Cordobesa, 19, II, Córdoba, 651-684.

López Melero, R. (1997), "Enterrar en Urso (Lex Ursonensis LXXIII-LXXIV)", Studia historica. Historia antigua, 15, 105-118.

López Quiroga, J. (2010), Arqueología del mundo funerario en la Península Ibérica (siglos V-X), Biblioteca Básica (Ergástula), 3, Madrid.

López Quiroga, J. y Martínez Tejera, A. M. (2009), "De Corporibus Defunctorum: Lectura e interpretación históricoarqueológica del canon XVIII del primer concilio de Braga (a. 561) y su repercusión en la arquitectura hispana de la Antigüedad Tardía”, en J. López Quiroga y A. M. Martínez (coord.), Morir en el Mediterráneo 
medieval, Archaeological Studies on Late Antiquity and Early Medieval Europe (400-1000 A.D.), Oxford, 151-170.

López Vilar, J. (2006), Les basiliques paleocristianes del suburbi occidental de Tarraco. El temple septentrional $i$ el complex martirial de Sant Fructuós, Sèrie Documenta, 4, Tarragona.

Lorencio, C. et alii (1998), "Enterraments infantils a l'edifici imperial de la Magdalena (Lleida)", Ítaca. Annexos, 1, 299-315.

Macías i Solé, J. M. et alii (dir.), (2007), Planimetria Arqueològica de Tàrraco, Sèrie Documenta, 5, Tarragona.

Mateos Cruz, P. (2005), "Los orígenes de la cristianización urbana en Hispania", VI Reunió d'Arqueologia Cristiana Hispànica, Barcelona, 49-62.

Meneghini, R. y SantangeliValenzani, R. (1993), "Sepolture intramuranee e paesaggio urbano a Roma tra V e VII secolo" en L. Paroli y P. Delogu (ed.) La storia economica di Roma nell'alto Medioevo alla luce dei recenti scavi archeologici, Firenze, 89-111

Meneghini, R. y SantangeliValenzani, R. (2004), Roma nell'altomedioevo. Topografia e urbanistica della città dal V al X secolo, Roma.

Mínguez Morales, J. A. (1989-1990), "Enterramientos infantiles domésticos en la Colonia Lepida/ Celsa (Velilla de Ebro, Zaragoza)", Caesaraugusta, 66-67, 105-122.

Molina Expósito, A. (2003), Informe-Memoria de la Intervención Arqueológica de Urgencia en calle Tejón y Marín $n^{\circ}$ 14, Córdoba, Informe de la Delegación Provincial de Cultura de la Junta de Andalucía, Córdoba (Inédito).

Nolla i Brufau, J. M. (1997), "Roses a l'antiguitat tardana. El cementiri de Santa María”, Annals de l'Institut d'Estudis Empordanesos, 30, 107-146.

Nolla i Brufau, J. M. y Aquilué Abadías, X.(1999), "Necròpoli de la Neàpolis d'Empúries", en $\mathrm{P}$. Palol y A. Pladevall (dir.), Del romà al romànic. Història, art $i$ cultura de la Tarraconense mediterrània entre els segles IV $i \mathrm{X}$, Barcelona, 274-275.

Nolla i Brufau, J. M. y Sagrera i Aradilla, J.(1996), Civitatis Impuritanae coementeria. Les necròpolis tardanes de la Neàpolis, Estudi General, 15, Girona.
Nolla i Brufau, J. M. y Sureda i Jubany, M. (1999), "El món funerari antic, tardoantic y altomedieval a la ciutat de Girona. Un estat de la qüestió", Annals de l'Institut d'Estudis Gironins, 40, 13-66.

Ortalli, J. (2003), "Linsediamento residenziale urbano nella Cispadana”, en J. Ortalli y M. Heinzelmann (a cura di), Abitare in città. La Cisalpina tra imperio e medioevo, Palilia 12, Wiesbaden, 95-119.

Padrós i Martí, P. (1999), "Ciutat de Bètulo", en P. Palol y A. Pladevall (dir.), Del romà al romànic. Història, art i cultura de la Tarraconense mediterrània entre els segles IV $i \mathrm{X}$, Barcelona, 89-90.

Palol i Salellas, P. (1991-1978), "Noves dades arqueològiques sobre els darrers segles de Clunia", Clunia VIII. O. Studia varia Cluniensia, Burgos, 295-300.

Palol i Salellas, P. (1994), Clunia. Historia de la ciudad y guía de las excavaciones, Burgos.

Pedro, I. y Inês Vaz, J. L. (1995), "Basílica e necrópole altomedievais de Viseu", IV Reunió d'Arqueologia Cristiana Hispànica, Barcelona, 343-352.

Pera Isern, J. (1999): “Necròpoli de Iesso”, en P. Palol y A. Pladevall (dir.), Del romà al romànic. Història, art i cultura de la Tarraconense mediterrània entre els segles IV $i \mathrm{X}$, Barcelona, 271-272.

Pera Isern, J. y Uscatescu Barrón, A. (2007): "La Antigüedad Tardía en la ciudad de Iesso (Guissona, Lérida). Una aproximación a través del análisis de algunos contextos estratigráficos", Madrider Mitteilungen, 48, Madrid, 204-266.

Pérez RodríguezAragón, F. (1997), "Elementos de tipo bárbaro oriental y danubiano de época bajoimperial en Hispania”, La Hispania de Teodosio, II, Salamanca, 629-647.

Puig Griessenberger, A. M. a (1999), "Món funerari de Roses", en P. Palol y A. Pladevall (dir.), Del romà al romànic. Història, art i cultura de la Tarraconense mediterrània entre els segles IV i X, Barcelona, 273-274.

Puig i Verdaguer, F. (1999), "Món funerari de Bàrcino", en P. Palol y A. Pladevall (dir.), Del romà al romànic. Història, art i cultura de la Tarraconense mediterrània entre els segles $I V i$ $X$, Barcelona, 265-270.

Ramallo Asensio, S. F. et alii (2010), "Cartha- 
go Nova y su espacio suburbano. Dinámicas de ocupación en la periferia de la urbs", en D. Vaquerizo (ed.), Las áreas suburbanas en la ciudad histórica. Topografía, usos y función, Monografías de Arqueología Cordobesa, 18, Córdoba, 211-254.

Ramallo Asensio, S. F. y Vizcaíno Sánchez, J. (2007), "Evolución del sistema defensivo de Cartagena durante la Antigüedad", Murallas de Cidades Romanas no Occidente do Impero. Lucus Augusti como paradigma, Lugo, 483-522.

Revilla Calvo, V. y Cela Espin, X. (2006), "La transformación material e ideológica de una ciudad de Hispania: Iluro (Mataró) entre los siglos I y VII", Archivo Español de Arqueología, $79,89-114$.

Ribera i Lacomba, A. V. y Rosselló Mesquida, M. (2000), "La ciudad de Valencia en época visigoda", Los orígenes del Cristianismo en Valencia y su entorno, Grandes Temas Arqueológicos 2, Valencia, 151-164.

Ribera i Lacomba, A. V. y Soriano Sánchez, R. (1987), "Enterramientos de la Antigüedad Tardía en Valentia", Lucentum, 6, 139-164.

Riera Rullán, M. et alii. (1999), "Els últims segles de Pollentia”, Bolletí de la Societat Arqueològica Lul-liana, 55, 335-346.

Ripoll López, G. (1999), "El món funerari”, en P. Palol y A. Pladevall (dir.), Del romà al romànic. Història, art $i$ cultura de la Tarraconense mediterrània entre els segles IV $i \mathrm{X}$, Barcelona, 249-260.

Román Rodríguez, J. M. (2001), "El almacenamiento de grano en Carmona. El horreum de San Blas”, en A. Caballos (ed.), Carmona Romana, Carmona, 233-250.

Román Rodríguez, J. M. (2009), "Excavación arqueológica preventiva en el solar $\mathrm{n}^{0} 3$ de la Plazuela Juan Facúndez de Carmona (Sevilla)", Anuario Arqueológico de Andalucía / 2004, I, 3132-3157.

Sales Carbonell, J. (2003), "Necrópolis cristianas tardoantiguas en el área catalana: estado de la cuestión”, en L. A. García Moreno et alii (ed.), Santos, obispos y reliquias, Alcalá de Henares, 319-333.

Salinas Villegas, J. M. (2005), "El sector septentrional de la villa romana de Santa Rosa”, Anales de Arqueología Cordobesa, 16, Córdoba, 35-54.
Sánchez Ramos, I. M.a (2006), La cristianización de la topografía funeraria en las provincias occidentales del imperio: exemplum cordubense, Tesis Doctoral dirigida por D. Vaquerizo y J. M. Gurt, Córdoba.

Schattner, T. G. (2003), Munigua. Cuarenta años de investigaciones, Junta de Andalucía, Sevilla.

Schattner, T. G. et alii (2006), "Sucinto informe de las investigaciones arqueológicas en Munigua", Anuario Arqueológico de Andalucía/2003, II, 66-77.

Serrano Peña, J. L. (2004), Aurgi. Estudio del municipio romano desde la arqueología urbana de Jaén, 1985-1995, Jaén.

Sevilla Conde, A. (2010-2011), "Mors inmatura en el mundo romano. Provincia Tarraconensis", Anales de Arqueología Cordobesa, 21/22, 197-220.

Sillières, P. (1997), Baelo Claudia. Una ciudad romana de la Bética, Collection de la Casa de Velázquez, 61, Madrid.

Treffort, C. (1996), "Du cimiterium christianorum au cimetière paroissial: évolution des espaces funéraires en Gaule du VIe au Xe siècle", en M. Galinié y E. Zadora-Rio (dir.), Archéologie du cimetière chrétien, 11e supplément à la Revue Archéologique du Centre, Tours, 55-64.

Vargas Cantos, S. (2005), AAP en la Unidad de Actuación U12 (Garaje Alcázar), Informe de la Delegación Provincial de Cultura de la Junta de Andalucía, Córdoba. 
